1. COMENTARIOS MONOGRAFICOS

\title{
ES OBLIGADO EL PAGO DEL IMPORTE DE LAS OBRAS REALIZADAS EN FAVOR DE UN AYUN- TAMIENTO AUNQUE EL CONTRATO SE HUBIERA CELEBRADO POR EL ALCALDE, CON INFRACCION DE LA NORMATIVA LEGAL
}

340.142: 352.712

por

\section{Nemesio Rodríguez Moro}

Esta es la conclusión a que llega la sentencia del Tribunal Supremo de 3 de noviembre de 1980 (Ar. 4255), al confirmar la sentencia apelada, en la que se había establecido que el Ayuntamiento de X debía pagar la cantidad de 1.072 .479 pesetas, más los intereses legales, a quien llevó a cabo la obra en virtud de contrato celebrado con el Alcalde.

La cuestión litigiosa, en síntesis, se produjo al negarse el Ayuntamiento Pleno a satisfacer dicha cantidad a quien, por contrato celebrado con el señor Alcalde-Presidente, había llevado a cabo las obras de reforma y mejora de la red y demás instalaciones municipales de alumbrado público en las calles y plazas del respectivo Municipio.

Las razones fundamentales en que se basaba la Corporación municipal demandada, defendida por el señor Abogado del Estado, eran la incompetencia de Jurisdicción contencioso - administrativa para entender del asunto y la inexistencia del contrato. 
En cuanto a la incompetencia de la Jurisdicción contencioso-administrativa, dice el Tribunal Supremo que se trata aquí de un típico contrato de ejecución de obra pública, y que, por tanto, este contrato está sometido al Derecho administrativo, y todas las cuestiones referentes a su cumplimiento, inteligencia, resolución y efectos es de la competencia de dicha Jurisdicción contencioso-administrativa. $Y$ ello con independencia de que se hayan alegado fuentes generadoras de obligaciones en el campo del Derecho civil, cuando estas obligaciones tienen igualmente aplicación en el campo del Derecho administrativo. De manera que si para exigir del Ayuntamiento el pago de las cantidades satisfechas por quien realizó las obras se invocan preceptos del Derecho civil, esto no desvirtúa ni cambia la naturaleza administrativa del contrato, y, por ello, la competencia de la Jurisdicción contencioso-administrativa para entender y resolver el asunto es incuestionable.

Tampoco acepta el Tribunal la alegación de que el contrato es nulo a radice por haberse prescindido del procedimiento legalmente establecido por el Reglamento de Contratación de las Corporaciones locales, y que por razón de esa nulidad el Ayuntamiento no tiene por qué hacer frente al pago de las obras realizadas. Y no acepta tal tesis no sólo por razones de equidad, sino también de seguridad jurídica. En efecto, si el patrimonio municipal se vio incrementado como consecuencia de aquellas obras, si no se pagasen éstas se daría una situación de enriquecimiento injusto, que la equidad rechaza, pues aun cuando deba manejarse con cautela este principio, en orden a establecer la justicia conmutativa, sin embargo, debe aplicarse especialmente en la contratación cuando se hubieren de producir desigualdades irritantes en las prestaciones recíprocas, ya que si una de las partes cumplió lo establecido está en su derecho de exigir que la otra parte haga frente a su compromiso.

Por otro lado, la seguridad jurídica saldría malparada si no fuera protegido el gestor de buena fe que, en este caso, contrató con el Alcalde, a quien él estimó suficientemente legitimado para llevar a cabo el encargo de las obras.

Hace alusión la sentencia a la doctrina de la negotiorum gestio, aplicable en el Derecho administrativo, y a la acción de in rem verso como base doctrinal para establecer la obligación que el Ayuntamiento tiene de pagar el importe de las obras realizadas en su favor, así como los intereses producidos por la prestación pecuniaria demorada indebidamente. También se refiere a la doctrina de la 
«conversión de los actos», pues aunque falten, dice, los elementos esenciales de formalización del contrato, no así los que se refieren a su existencia, se dan los suficientes para afirmar que existe un cuasicontrato de gestión de negocios ajenos.

En conclusión, que la sentencia condena al Ayuntamiento a pagar el importe de la obra que fue encomendada al demandante por el Alcalde-Presidente del Ayuntamiento, más los intereses legales correspondientes.

Los Considerandos de la sentencia son del tenor literal siguiente:

\section{Considerandos de la sentencia apelada:}

ConsIderando: Que de las alegaciones de las partes no negadas, del expediente administrativo y de la prueba practicada, examinado todo con arreglo a la sana crítica, procede sentar como probado que en el año 1962 el Alcalde Presidente de la Corporación demandada contrató con la Compañía recurrente la realización de un proyecto de reforma y mejora de la red y demás instalaciones municipales de alumbrado público en las principales plazas y calles y convino además con la Compañía recurrente que la obra la efectuasen A., S. A., y don José P. P. y que sufragase el coste de dicho proyecto pagando a éstos las correspondientes certificaciones que fueron conformes al proyecto y presupuesto, que después le serían reintegrados por dicha Corporación; las obras se realizaron durante los años 1962 y 1963, y si bien a las efectuadas por A., S. A., en un principio se puso reparos por la Corporación local, tanto éstas como las realizadas por el señor $P$. fueron aceptadas por el señor Alcalde $y$ por el perito industrial municipal, y su importe de 1.072.479,84 pesetas satisfecho por la Compañía recurrente a dichos contratistas entre el 30 de noviembre de 1962 y el 16 de marzo de 1965; la actora verbalmente y por escrito ha reiterado de la Corporación demandada el abono de dicha cantidad sin conseguirlo; de estas reclamaciones por escrito cabe destacar la de 22 de noviembre de 1966 (folio 1 del expediente), 9 de junio de 1972 (folio 10 del expediente) y 21 de julio de 1975 (folio 38 del expediente) y de las numerosas reclamaciones verbales el reconocimiento que hizo el Alcalde al contestar en el pleito civil a la pregunta sexta que se le formulo (folios 124 y 138 vuelto de los autos).

Considerando: Que frente a estos hechos probados hay que contemplar la pretensión de pago de la Compañía recurrente y que basa en los artículos 1.709 y siguientes, 1.892 y siguientes del Código Civil, en la teoría del enriquecimiento injusto, así como la oposición de la Corporación demandada: a) Incompetencia de jurisdicción; b) inexistencia del contrato, y c) prescripción.

ConsIDERANDO: Que conforme a las disposiciones adicionales 1.a y 2.a del Reglamento de Contratación de las Corporaciones locales, los contratos en que intervengan éstas se regirán por dicho Reglamento y en lo no previsto 
en él por las disposiciones aplicables a la Administración General del Estado y, en su defecto, por las disposiciones pertinentes del Derecho Privado; el contrato de obras públicas no es más que la aplicación a esta clase de obras del contrato de ejecución de obras por ajuste o precio alzado regulado en la Sección segunda del Capítulo III del Título VI, Libro IV del Código Civil; Capitulo denominado "Del arrendamiento de obras y servicios», razón por la cual la Sala de lo Civil de esta Audiencia, en la sentencia dictada en el pleito civil que hubo entre las mismas partes aquí contendientes (folio 78 autos), calificó al contrato debatido como de "arrendamiento de obra atinente a un servicio público -alumbrado de población-"; calificación que se estima correcta con la única variación de que la Sala estima que se trata de un típico contrato de ejecución de obra pública; dicho contrato está sometido al Derecho Administrativo -art. 41." de la L. C. Estado de 17 de marzo de 1973-, y todas las cuestiones referentes a su cumplimiento, inteligencia, resolución y efectos es de la competencia de la Jurisdicción contencioso-administrativa -artículo 3-a de la Ley Jurisdiccional (L. C. Estado citada)--; por ello, si para cobrar el contratista lo que se le debe se invocan preceptos del Código Civil, esto no desvirtúa la naturaleza del contrato, ni que la cuestión que se debate no sea de competencia de esta Sala, pues como dice la sentencia del Tribunal Supremo de 22 de enero de 1975, «aparte o con independencia de la perspectiva contractual no puede ignorarse la existencia en el campo del Derecho Administrativo de otras fuentes de las que surgen obligaciones de tal carácter, tales como la llamada gestión de negocios de la Administración, trasplante a este campo de la teoría de la negotiorum gestio, que si bien una parte de la doctrina combate en base de la prohibitio domini, la mayoría admite la posibilidad, al menos, del ejercicio de una acción in rem verso, sirviéndole de soporte el enriquecimiento experimentado, en este caso - al igual que el de autos--, por el patrimonio del Ayuntamiento demandado y tendente a cubrir el hueco dejado por el acto nulo y proteger subsiguientemente el gestor de buena fe que merece amparo no sólo por razones de equidad, sino también de seguridad juridica, ya que obró confiadamente, lealmente, al entender suficientes las garantías dadas por el Alcalde, aparentemente legitimado... para convenir la realización de la obra de autos; por otro lado, también puede hablarse de la aplicación de la doctrina de la conversión de los actos administrativos, pues aunque falten los elementos esenciales de formalización del contrato (no asi respecto de su existencia), se dan, no obstante, los precisos para afirmar que existe un cuasi-contrato de gestión de negocios ajenos entre la Corporación demandada y el actor reclamante, por desprenderse de los autos igual que en este proceso que el encargo de la obra fue realizado indudablemente sin contar... con autorización suficiente, y que una vez realizada la misma... se integró en el patrimonio municipal, beneficiándose o enriqueciéndose con la misma»; por tanto, procede desestimar la causa de inadmisibilidad de incompetencia de jurisdicción invocada por el Abogado del Estado.

CONSIDERANDO: Que en cuanto a la supuesta inexistencia del contrato por haberse prescindido del procedimiento legalmente establecido por el Reglamento de Contratación de las Corporaciones locales, no puede ser atendida, pues, aparte de reiterar lo dicho por el Tribunal Supremo en la sentencia que 
se acaba de indicar en orden a cubrir el hueco dejado por el acto nulo, como bien dice la sentencia del mismo Alto Tribunal de 10 de noviembre de 1975 y la anterior citada de 22 de enero de 1975 entre otras, anadie puede invocar a su favor el motivo de nulidad que haya originado y que si es verdad que hayan de manejarse con cautela los arbitrios de equidad, tendentes a establecer la justicia conmutativa, su observancia es llamada especialmente en la contratación, cuando se hubieren de producir desigualdades irritantes en las prestaciones reciprocas que la informan por las conductas interesadas y que si la Empresa contratante rindió su obra, pugnaría con la mentada justicia y no sería conforme a derecho, que se beneficiare de ella la otra parte contratante liberándose del pago de su encargo..., creándose una situación de enriquecimiento injusto en perjuicio de una de las partes y en beneficio de la otra».

CONSIDERANDo: Que ante preceptos administrativos específicos referentes a prescripción de créditos por prestación de servicios y obras, cuales son el artículo 796-2-a de la Ley de Régimen local y 25 de la Ley de Administración y Contabilidad del Estado, no tiene aplicación al presente caso el plazo de prescripción del artículo 1.964 del Código Civil, ya que como se dijo al principio del tercer considerando, las normas de Derecho Privado son de aplicación subsidiaria; por tanto, el plazo de prescripción es el de cinco años y así lo reconocen las sentencias del Tribunal Supremo de 16 de diciembre de 1971 y de 4 de diciembre de 1974; conforme a la primera de éstas, la cual confirma una sentencia de esta Sala, antes de enfrentarnos con los hechos conviene "dejar' constancia de la necesidad de extremar el celo en el manejo de una institución tan delicada, como es la prescripción, en cuanto la misma viene a frustrar el logro de la justicia, en aras de la seguridad, máxime cuando, como aquí ocurre -igual que en autos-, se trata de un caso de justicia conmutativa, esto es, un supuesto en que lo reclamado arranca de una situación sinalagmática, de do ut facias, en la que una parte, la parte individual y particular de la relación, ha cumplido sus obligaciones y compromisos (la realización de la obra contratada), mientras que la contraria, la Administración, no ha hecho lo propion, $y$ añadir, con palabras de dicha sentencia, respecto a la interrupción de la prescripción, "que si del lado de la Administración, el reconocimiento de deudas, por parte de la misma, se ha vinculado a reconocimientos expresos - no tácitos-, e incluso a reconocimiento de tipo documental y solemnes, como se exige en el... artículo 293-2 del Reglamento de Haciendas Locales, por el contrario, del lado del acreedor no se ha exigido-a los efectos que nos ocupan de la interrupción de la prescripción-más que la simple reclamación del acreedor, sin más distinciones, lo que convierte en ilicito cualquier clase de distinción, no querida por el «legislador»; efectivamente, en el presente caso desde el 22 de noviembre de 1960 al 9 de junio de 1972, es decir, durante cinco años, seis meses y diecinueve días no existe constancia por escrito de reclamaciones de la Entidad recurrente a la Corporación demandada, pero eso no quiere decir que no las hubiera verbalmente mediante entrevistas personales, y así hay que estimarlo, por lógica y por reconocimiento del Alcalde; en efecto, resulta absurdo que la Entidad actora, tras múltiples gestiones por escrito, después de la remisión de las siete certificaciones en la primera fecha indicada, se olvida de la cantidad que se le debe 
hasta que en la segunda fecha hace su reclamación gubernativa previa a la judicial, máxime cuando el Alcalde reconoce el reiterado planteamiento del tema del reintegro del desembolso después de la visita de año 1964, que fue la que motivó el envío de las certificaciones aludidas, tanto a él como al Interventor, añadiendo «que el Ayuntamiento estaba buscando una fórmula para pagar a la Compañía Sevillana de Electricidad, pero que legalmente no la encontraba»; que ante estos hechos no hay más remedio que estimar que ante estas reiteradas reclamaciones que no han dejado un intervalo superior a los cinco años sin hacerse, no se ha producido la prescripción.

ConsIDERANDo: Que acreditado la celebración del contrato, la realización de la obra, el importe y el pago de la misma por la Entidad recurrente, se impone acceder integramente a la demanda, ya que conforme al artículo 942 del Reglamento de Contratación de las Corporaciones locales procede el abono de los intereses de demora.

ConsIDERANDo: Que no es de estimar temeridad ni mala fe para hacer una expresa imposición de costas.

\section{Considerando del Tribunal Supremo:}

CONSIDERANDo: Que sobre la realidad fáctica de unas obras ejecutadas por la Compañía Sevillana de Electricidad en el Municipio de Peñarroya-Pueblo Nuevo, bien sobre un soporte jurídico contractual de mandato o de típica ejecución, de obra o, hasta si se prefiere, en el campo de las hipótesis, una gestión de negocios ajenos, el hecho admitido por la propia Administración apelante de las referidas obras implicaría, en el supuesto de denegarse la pretensión indemnizatoria, un evidente incumplimiento contractual por parte del Ayuntamiento o un enriquecimiento sin causa si se basase aquella pretensión en la gestión alegada, lo cual lleva necesariamente al reconocimiento del derecho de la Empresa demandante al resarcimiento de su actividad y a confirmar la sentencia recurrida, sin hacer expresa imposición de costas. 